\title{
Theoretical study of the molecular properties of doubly ionized carbon monoxide
}

\author{
Santos, F; Alves, M. D. S; Silva, S. R. and Ballester, M. Y \\ Universidade Federal de Juiz de Fora, Juiz de Fora, Minas Gerais, Brazil \\ ufjf.felipe@gmail.com \\ marcosalves@ ice.ufjf.br
}

\begin{abstract}
Doubly charged diatomic molecules are species which has been subject to experimental and theoretical investigation. Among the various species we concentrated here in to study the molecular properties of the $\mathrm{CO}^{2+}$. In this analysis, we consider the following singlet and triplet electronic states $\mathrm{X}^{3} \Pi, \mathrm{b}^{1} \Pi, \mathrm{A}^{3} \Sigma^{+}$, and $\mathrm{a}^{1} \Sigma^{+}$. The spectroscopic constants calculated have been compared with the experimental measures and the state-of-the-art theoretical methods.
\end{abstract}

\section{Introduction}

The investigation of doubly charged carbon monoxide increasingly attracting the interest of experimentalists and theoreticians. A good description of the molecular properties these ions are very important to improve understand of reactions such as [1, 2, 3]

$$
\begin{aligned}
\mathrm{CO}^{2+}+\mathrm{M} & \rightarrow \mathrm{CO}^{+}+\mathrm{M}^{+}+\Delta \mathrm{E} \\
\mathrm{CO}^{2+}+\mathrm{Ar} & \rightarrow \mathrm{ArC}^{2+}+\mathrm{O} \\
\mathrm{CO}^{2+}+\mathrm{Kr} & \rightarrow \mathrm{CO}^{+}(\mathrm{D})+\mathrm{Kr}^{+} \\
& \rightarrow \mathrm{C}^{+}+\mathrm{O}+\mathrm{Kr}^{+}
\end{aligned}
$$

where $\mathrm{M}$ represents different rare gases, while $\Delta \mathrm{E}$ is the energy for the electroncapture reaction.

Experimentally, tecniques such as Auger spectroscopy [4, 5] and electron impact [6] have been employed to look into the $\mathrm{CO}^{2+}$ dication. From the theoretical point view, Eland et al. performed electronic structure calculations using a state-averaged full valence complete active space self-consistent field (CASSCF) and internally contracted multireference configuration interaction (MRCI) approaches associate to cc-pV5Z (V5Z) basis set to compute the potential energy curves of $\mathrm{CO}^{2+}$ as well as for $\mathrm{CO}$ in its ground state [7]. Ref. [8] present a refined study relative to the vibronic (vibration-electronic) transition parameters as Franck-Condon factors for the bands $a^{1} \Sigma^{+} \rightarrow X^{3} \Pi, \quad b^{1} \Pi \rightarrow X^{3} \Pi$, $\mathrm{A}^{3} \Sigma^{+} \rightarrow \mathrm{X}^{3} \Pi$, and $\mathrm{b}^{1} \Pi \rightarrow \mathrm{a}^{1} \Sigma^{+}$systems of $\mathrm{CO}^{2+}$ dication.

However, in none of these works an analytical form to describe the interaction energy is shown. In this scenario, we 


\section{Blucher Proceedings X Encontro Científico de Física Aplicada Blucher}

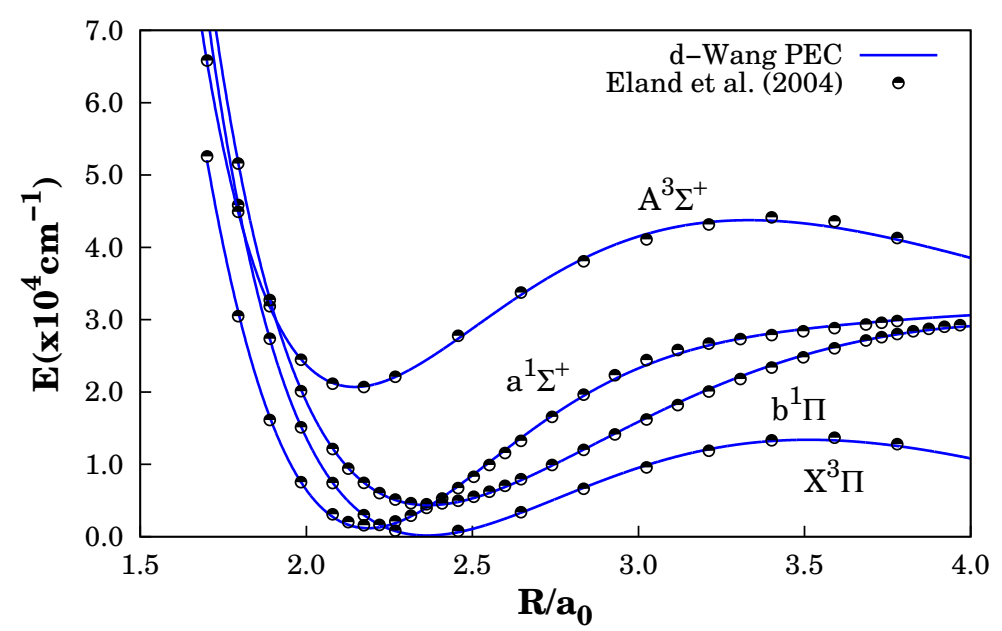

Figure 1: Potential energy curves for ground and three excited states of $\mathrm{CO}^{2+}$ dication. Ab initio points from [7] are also represented.

have utilized the modified version of the Wang's function to calculate the molecular properties of the $\mathrm{CO}^{2+}$ specie. In particular, the singlet and triplet electronic states $X^{3} \Pi, a^{1} \Sigma^{+}, b^{1} \Pi$, and $A^{3} \Sigma^{+}$were considered.

So, we organized the article as follows: Section 2 describes the analytic representation to potential energy curves (PECs) used in this work. Our results are discussed in Section 3 and the concluding remarks are given in the last section.

\section{Analytical PEC}

The analytical PECs for ground and three electronically excited states were constructed based on the modified version of the Wang's representation reported by Machado et al., so-called "d-Wang", defined as [9]:

$$
\mathrm{V}_{\mathrm{d}}(\mathrm{R})=\left(\sum_{\mathrm{n}=0}^{\mathrm{N}-1} \mathrm{a}_{\mathrm{n}} \mathrm{R}^{\mathrm{n}}\right) \mathrm{e}_{\mathrm{d}}^{-\mathrm{a}_{\mathrm{N}} \mathrm{R}}+\frac{\mathrm{C}}{\mathrm{R}}
$$

where

$$
\mathrm{e}_{\mathrm{d}}^{-\mathrm{aR}}=(1-\mathrm{daR})^{\frac{1}{\mathrm{~d}}}
$$

in Eq. (1), the first term is the Varandas potential term and the last one is a repulsive ionic Coulombic term. C, d, and $a_{n}$ are adjustable parameters and $\mathrm{R}$ stands for the internuclear distance.

To study the diatomic fragment $\mathrm{CO}^{2+}$ we extracted $a b$ initio electronic energies from Ref. [7]. Once obtained these data, the parameters of the Eq. (1) have been fitted using the least-squares method. This is the procedure followed by Machado et al. to obtain the spectroscopic constants and the rovibrational spectra for homo- and heteronuclear molecules $\mathrm{Be}^{2+}, \mathrm{He}^{2+}, \mathrm{BH}^{2+}$, and $\mathrm{NH}^{2+}$.

\section{Results}

We start this discussion comparing in Fig. 1 the $a b$ initio PECs from Ref. [7] with our interaction energies as a function of internuclear distances. As can be seen, the modeled potential accurately mimics the $a b$ initio energies. It is interesting to analyze the values of d-parameter. Here we obtain the following values: -0.014 
Table 1: Spectroscopic parameters for the ground and excited electronic states of $\mathrm{CO}^{2+}$ calculated using Eq. (1). Theoretical and experimental data are also included.

\begin{tabular}{|c|c|c|c|c|c|}
\hline $\begin{array}{c}\text { State } \\
\text { designation }\end{array}$ & Method & $\begin{array}{l}\mathrm{R}_{\mathrm{e}} \\
\left(\mathrm{a}_{0}\right)\end{array}$ & $\begin{array}{c}\omega_{\mathrm{e}} \\
\left(\mathrm{cm}^{-1}\right)\end{array}$ & $\begin{array}{c}\omega_{\mathrm{e}} \mathrm{X}_{\mathrm{e}} \\
\left(\mathrm{cm}^{-1}\right)\end{array}$ & $\begin{array}{c}\mathrm{D}_{\mathrm{e}} \\
\left(\mathrm{cm}^{-1}\right)\end{array}$ \\
\hline \multirow[t]{4}{*}{$x^{3} \Pi$} & d-Wang & 2.3633 & 1443.5 & 38.51 & 13525.8 \\
\hline & Theo. [10] & 2.3621 & 1396.3 & 36.49 & 13308.1 \\
\hline & Exp. [7] & 2.3581 & 1435.2 & 24.60 & - \\
\hline & Exp. [5] & 2.3640 & 1451.8 & 28.22 & - \\
\hline \multirow[t]{4}{*}{$\mathrm{a}^{1} \Sigma^{+}$} & d-Wang & 2.1862 & 2038.2 & 34.68 & 29944.4 \\
\hline & Theo. [10] & 2.1920 & 1946.6 & 30.14 & 32262.1 \\
\hline & Exp. [7] & 2.1906 & 1920.5 & 16.70 & - \\
\hline & Exp. [5] & 2.2034 & 1904.2 & 20.16 & - \\
\hline \multirow[t]{4}{*}{$b^{1} \Pi$} & d-Wang & 2.3673 & 1495.5 & 21.93 & 25020 \\
\hline & Exp. [7] & 2.3621 & 1487.7 & 17.20 & - \\
\hline & Exp. [5] & 2.3772 & 1455.0 & 15.32 & - \\
\hline & Exp. [5] & 2.3432 & 1521.0 & 17.74 & - \\
\hline \multirow[t]{4}{*}{$\mathrm{A}^{3} \Sigma^{+}$} & d-Wang & 2.1535 & 2026.9 & 43.32 & 23044 \\
\hline & Exp. [7] & 2.1444 & 2043.8 & 16.30 & - \\
\hline & Exp. [5] & 2.1467 & 2108.3 & 39.52 & - \\
\hline & Exp. [5] & 2.1486 & 2070.0 & 37.00 & - \\
\hline
\end{tabular}




\section{Blucher Proceedings X Encontro Científico de Física Aplicada Blucher}

to $\mathrm{X}^{3} \Pi,-0.009$ to $\mathrm{a}^{1} \Sigma^{+},-0.094$ to $\mathrm{b}^{1} \Pi$, and -0.058 to $\mathrm{A}^{3} \Sigma^{+}$. Looking into results, it is possible to note that larger values of d lead us to smaller depth of the potential well. Based on the APECs obtained we calculate the spectroscopic parameters for $\mathrm{CO}^{2+}$ dication.

Table 1 summarize the spectroscopic parameters determined from Eqs. (1) and (2). Column one of this table indicates the electronic state of $\mathrm{CO}^{2+}$ dication, whereas the different methods are given in column two. The bond distances $\left(\mathrm{R}_{\mathrm{e}}\right)$ are present in the third column and the harmonic vibrational frequencies calculated $\left(\omega_{\mathrm{e}}\right)$ are listed in fourth column. The fifth and sixth columns of Table 1 show the first anharmonicity constant $\left(\omega_{\mathrm{e}} \mathrm{X}_{\mathrm{e}}\right)$ and the well depth $\left(\mathrm{D}_{\mathrm{e}}\right)$, respectively. We highlight that spectroscopic constants taken from Ref. [10] correspond to coupled-cluster singles and doubles augmented by a perturbative treatment of triple excitations $(\operatorname{CCSD}(\mathrm{T}))$ using correlated consistent cc-pVTZ (VTZ) basis set.

The calculated equilibrium bond length for the ground electronic state is $2.3633 \mathrm{a}_{0}$ which is only $0.0052 \mathrm{a}_{0}$ smaller than experimental data [7]. For the other excited states we found deviations of $0.0044 \mathrm{a}_{0}$ for $\mathrm{a}^{1} \Sigma^{+}, 0.0052 \mathrm{a}_{0}$ for $\mathrm{b}^{1} \Pi$, and $0.0091 \mathrm{a}_{0}$ for $\mathrm{A}^{3} \Sigma^{+}$. In relation to theoretical data, there is a good overall agreement between the $\operatorname{CCSD}(\mathrm{T}) / \mathrm{VTZ}$ bond lenghts for states $X^{3} \Pi$ and $a^{1} \Sigma^{+}$ and our calculated values.

In the case of the ground-state $X^{3} \Pi$ the vibrational frequency, $\omega_{\mathrm{e}}$, our result is better than that those reported with CCSD(T)/VTZ level of theory when compared with experimental ones. On the contrary, we can also observe for $\omega_{\mathrm{e}} \mathrm{X}_{\mathrm{e}}$ relative differences of $2.02 \mathrm{~cm}^{-1}$ from Ref. [10], $13.91 \mathrm{~cm}^{-1}$ from [7], and 10.29 $\mathrm{cm}^{-1}$ from [5]. The difficulty in provid- ing a proper description of $D_{e}$ is evident at the various levels of theoretical and experimental investigations. A more detailed analysis is being prepared aiming this issue.

The calculated molecular spectroscopic parameters for $\mathrm{a}^{1} \Sigma^{+}$states agree reasonably well with experimental ones except the values for the vibrational anharmonicity. The agreements of our results for singlet state $b^{1} \Pi$ with those from Ref. [7] is noticeable. Yet, relatives deviations of $\Delta \mathrm{R}_{\mathrm{e}}=0.0052 \mathrm{a}_{0}, \Delta \omega_{\mathrm{e}}=7.8$ $\mathrm{cm}^{-1}$, and $\Delta \omega_{\mathrm{e}} \mathrm{X}_{\mathrm{e}}=4.73 \mathrm{~cm}^{-1}$ it can be visualized.

To finish this section, Taking the fundamental frequency for triplet state $\mathrm{A}^{3} \Sigma^{+}$, our calculation was 16.9, 81.4 and 43.1 $\mathrm{cm}^{-1}$ smaller than Refs. [7] and [5], respectively. In our present work, the vibrational anharmonicity determined overestimate the experimental measures from [5] in 3.8 and $6.32 \mathrm{~cm}^{-1}$. We also notice that the deviation associated to Ref. [7] is $27.02 \mathrm{~cm}^{-1}$, i.e., it represents an unsatisfactory value of deviation.

\section{Conclusion}

This paper reports the results from a theoretical study in which the potential energy curves for four states of $\mathrm{CO}^{2+} \mathrm{di}-$ cation were constructed using the modified analytical representation of Wang. The spectroscopic parameters obteined from these APECs agree well with available literature. For this reason, we belive that this work should be a good reference for the future research involving carbon monoxide doubly-charged ions. 


\section{Acknowledgments}

The authors gratefully thank CAPES and BIC/UFJF for financial support.

\section{References}

[1] KRISHNAMURTHI, V. et al., Phys. Rev. A, v. 44, p. 5460, 1991.

[2] PRICE, S.D., Int. J. Mass Spectrom., v. 260, p. 1-19, 2007.

[3] PRICE, S.D. et al., Int. Rev. Phys. Chem., v. 36, p. 145-183, 2017.

[4] CURTIS, J.M.; BOYD, R.K., J. Chem. Phys., v. 80, p. 1150-1161, 1984.
[5] PÜTTNER, R. et al., Chem. Phys. Lett., v. 445, p. 6-11, 2007.

[6] HILLE, E.; MÄRK, T.D., J. Chem. Phys., v. 69, p. 4600-4605, 1978.

[7] ELAND, J.H.D. et al., J. Phys. B: At. Mol. Opt. Phys, v. 37, p. 3197, 2004

[8] SEDIVCOVÁ-UHLÍKOVÁ, T. et al., Int. J. Quantum Chem., v. 107, n. 14, p. 2654-2664, 2007.

[9] MACHADO, D.F.S. et al., J. Mol. Model., v. 23, p. 182, 2017.

[10] MONDAL, B. et al., Int. J. Quantum Chem., v. 109, p. 469-476, 2009. 